\title{
Melatonin Inhibitory Effects on Forming Brain Tumor
}

\author{
Samaneh Khodadadi* \\ Department of Biology, Islamic Azad University, Iran
}

Submission: February 17, 2020; Published: March 11, 2020

*Corresponding author: Samaneh Khodadadi, Department of Biology, Falavarjan branch, Islamic Azad University, Isfahan, Iran

\begin{abstract}
Melatonin is a neurohormone secreted by the pineal and extra pineal organs with oncostatic and tumor inhibitory effects. There is considerable evidence that melatonin may be of use in the prevention and treatment of cancer. This manuscript will review some of the underlying molecular mechanisms by melatonin's antitumor properties with emphasizing on the formation of brain tumors.
\end{abstract}

Keywords: Melatonin; Brain tumor; Glioblastoma stem-like cell

\section{Introduction}

Central nervous system tumors contain many separate types of tumors in the brain parenchyma, meninges, and spinal cord. They can be divided into primary or secondary/metastatic tumors, benign or malignant tumors, based on the WHO classification with varying prevalence and assigned into four grades, from a very benign tumor to highly malignant tumors (Grade I to IV). Gliomas (intra-axial tumors inside brain/spinal cord parenchyma) are the most common malignant types with $75 \%$ prevalence than astrocytomas, oligodendrogliomas, mixed oligoastrocytomas, medulloblastomas (MBs), midline diffuse astrocytoma, diffuse intrinsic pontine gliomas (DIPG) and hemangioblastomas (HMBs) $[1,2]$.

Melatonin is L-tryptophan derivatives neurohormones secreted predominantly in the brain (cerebellum and cerebral cortex, raphe nuclei, striate body), spinal cord, retina, lens, cochlea, skin, gastrointestinal tracts such as the stomach, small and intestine, lymphocytes, bones, murine bone marrow, platelets, testes, and ovaries. In the neuro-endocrinal system, melatonin has a crucial role in energy metabolism and its secretion is stimulated by darkness and decreased by light, serum levels peaking between 2 a.m. and 5 a.m. Also, it has some other functions such as synthesis, distribution and divers' action of different receptors in the specific area of the brain, cellular signaling, and messenger system. Rise melatonin levels in the blood during the night could send signals to the body's cells and organs into appropriate homeostatic metabolic rhythms. Therefore, melatonin secretion disruption can lead to the progression of target organs cancer [3-5]. This mini review highlights the underlying mechanism by melatonin's antitumor properties with emphasizing on the formation of brain tumor.

\section{Melatonin and Tumor Growth Inhibition}

Melatonin acts as a hormone and based on accumulating data in the last decade also as a cell protector, involved in immunomodulation, antioxidative processes, and hematopoiesis [5]. Several experimental studies have highlighted that melatonin has neuroprotective benefits when given as either a prophylactic or curative treatment in several animal models of brain damage [6]. In 2019, Maitra and et al revealed that melatonin deficiency not only can have a debilitating effect on normal physiology, also can create some abnormal conditions such as malignancy in the brain and finally can lead to glioma. Hence, it can account for high expectations to be included as an adjuvant in cancer treatments $[3,7,8]$.

In 2013, QU and et al with the hypothesis that melatonin may have an inhibiting role in the apoptotic pathway and beneficial efficacy in the prevention of cancer, have investigated the different concentrations of melatonin on C6 glioma cell. They opt them because these cell lines are susceptible to expressing MT1 and MT2 receptors of melatonin, therefore they can be modulated by 
melatonin at a pharmacological concentration to the treatment of glioma. They also transcriptional regulation of three involved genes (Nestin, Bmi-1, and Sox2) in developing the nervous system as differentiation and proliferation markers in neural cells. In this study melatonin with $3 \mathrm{mM}$ concentration increase the mRNA levels of Nestin, Bmi-1, and Sox2 in a similar pattern, with the highest mRNA levels. At $5 \mathrm{mM}$ concentrations of melatonin, the mRNA levels of Nestin, Bmi-1, and Sox2 were reduced and were correlated with changes ocurred in survival assays [7]. The new therapeutic strategies of brain tumors focusing on glioblastoma with a subpopulation of stem-like cells responsible for glioma proliferation, therapeutic resistance, and tumor recurrence [4,9].

Notably, glioblastoma stem-like cells (GSCs), as protagonists in glioma growth scenarios, can increase tumor-initiating capacity. The results of a research conducted by Chen and et al in 2016, on the effects of melatonin in GSC biology, represent the high capability of melatonin in suppressing self-renewal properties of GSCs. A possible explanation of the anti-oncogenic role of melatonin might be that, it can mediate silencing of transcription factor STAT3 signaling through direct EZH2-STAT3 interaction and contributes to the transcriptional inactivation of H3K27me3 through EZH2 S21 dephosphorylation in GSCs [9]. GSCs and confirmed their claim through Neurosphere-forming assay. The storyline related by this scenario was the reduction in the expression levels of EZH2 and following that they found more strikingly NOTCH1 as a downstream target of EZH2 and core molecule in transfer EZH2-mediated signals which coincidentally has been reduced by melatonin in the GSCs $[10,11]$.

\section{Conclusion}

This manuscript investigated some instances of the beneficial outcomes in reducing malignant brain tumor formation by melatonin. Moreover, there is a lack of studies focusing on precise molecular mechanisms by melatonin in different types of brain tumors. Subsequently, more in-depth studies are needed to find therapeutic and preventive strategies through the use of melatonin for all types of brain tumors. Because not only melatonin has extraordinary properties in human physiology, it also is chemically synthesized and available for further investigations.

\section{References}

1. Whittier KL, Boese EA, Gibson-Corley KN, Kirby PA, Darbro BW, et al. (2013) G-protein coupled receptor expression patterns delineate medulloblastoma subgroups. Acta Neuropathol Commun 1: 66.

2. Wood MD, Halfpenny AM, Moore SR (2019) Applications of molecular neuro-oncology - a review of diffuse glioma integrated diagnosis and emerging molecular entities. Diagn Pathol 14(1): 29.

3. Maitra S, Bhattacharya D, Das S, Bhattacharya S (2019) Melatonin and its anti-glioma functions: a comprehensive review. Rev Neurosci 30(5): 527-541.

4. Zheng X, Bo Pang B, Gu G, Gao T, Zhang R, et al. (2017) Melatonin inhibits glioblastoma stem-like cells through suppression of EZH2NOTCH1 signaling axis. Int J Biol Sci 13(2): 245-253.

5. Li Y, Li S, Zhou Y, Meng X, Zhang JJ, et al. (2017) Melatonin for the prevention and treatment of cancer. Oncotarget 8(24): 39896-39921.

6. Olivier P, Fontaine RH, Loron G, Steenwinckel VS, Biran V, et al (2009) Melatonin promotes oligodendroglial maturation of injured white matter in neonatal rats. PLoS ONE 4(9): e7128.

7. Qu J, Rizak JD, Li X, Li J, Ma Y, et al (2013) Melatonin treatment increases the transcription of cell proliferation-related genes prior to inducing cell death in C6 glioma cells in vitro. Oncol Lett 6: 347-352.

8. Menendez-Menendez J, Martinez-Campa C (2018) Melatonin: An antitumor agent in hormone-dependent cancers. Int J Endocrinol 2018: 327194.

9. Chen X, Hao A, Li X, Du Z, Li H, et al (2016) Melatonin inhibits tumorigenicity of glioblastoma stem-like cells via the AKT-EZH2STAT3 signaling axis. J Pineal Res 61(2): 208-217.

10. Magrini S, Feletti A, Marton E, Longatti P (2013) Gliomas of the pineal region. J Neurooncol 115(1): 103-111.

11. Bondy SC, Campbell A (2018) Mechanisms underlying tumor suppressive properties of melatonin. Int J Mol Sci 19(8).

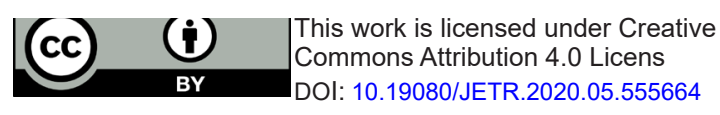

Your next submission with Juniper Publishers
will reach you the below assets
- Quality Editorial service
- Swift Peer Review
- Reprints availability
- E-prints Service
- Manuscript Podcast for convenient understanding
- Global attainment for your research
- Manuscript accessibility in different formats
( Pdf, E-pub, Full Text, Audio)
- Unceasing customer service
Track the below URL for one-step submission
https://juniperpublishers.com/online-submission.php

